\title{
VALUE IN USE OF PASEK DUNITE IMPROVING THE RETURN SINTER FINES*
}

\author{
Aitor Elorriaga Fernandez de Arroyabe ${ }^{1}$ \\ Javier Martinez Rubio ${ }^{2}$ \\ Pamela Diaz Garcia ${ }^{3}$ \\ Alba Fernandez Fernande ${ }^{4}$
}

\begin{abstract}
The purpose of Sinter plants is to heat iron ore fines along with fluxes and coke fines or coal, to produce a semi-molten mass that solidifies into porous pieces of sinter with the needed size and strength. Fluxes used in the sintering process need to have an appropriate size distribution and TI to avoid generation of fines, which could reduce the productivity of the Sinter. Besides, a homogeneous chemical composition and high absorption characteristics are necessary to control the basicity and to combine the flux with $\mathrm{P}, \mathrm{S}, \mathrm{Si}$, etc, respectively. PASEK Dunite is an ultramaphic rock exploited in the north of Spain with a basic chemical classification, being olivine and serpentine its principal minerals. It is a very homogeneous and hard stone and its main characteristics are: high hot and cold resistance to mechanical stresses, softening and melting points of a flux not of a refractory material. In addition, due to its mechanical and chemical properties, less fines are generated in the sintering process and during the handling and transportation to the blast furnace, improving the productivity of these processes. In this way, the use of PASEK Dunite allows increasing the homogeneity structure of sinter, reducing the percentage of return fines and improving the Sinter productivity.
\end{abstract}

Keywords: Fluxes; Dunite; Sinter; Return Fines; Magnesium Silicate.

Mechanical Engineer, Operation \& Marketing Director, Pasek Minerales, function, section/department, Institution of work or study, city, state, country.

Mining Engineer, General Manager, Pasek Minerales, Salinas, Asturias, Spain.

Chemical Engineer, R\&D Manager, Pasek Minerales, Salinas, Asturias, Spain.

Chemical Engineer, R\&D Technician, Pasek Minerales, Salinas, Asturias, Spain. 


\section{INTRODUCTION}

Magnesium silicates are commonly used as blast furnace (BF) fluxing additives, not only to adjust the slag $\mathrm{MgO}$ content, but also to promote potassium elimination with the slag and limit the harmful accumulation of potassium in the stack [1].

Quarried, crushed, sized and screened fluxes are added to the blast furnace in small quantities to perform the following functions:

- Magnesia addition, to fluidify the slag and adjust its MgO content to the optimum value (6 to $9 \%$ ), required by its basicity index and alumina content [2].

- Adjustment of the slag volume to its optimum value, connected to the slag basicity index.

- Improvement of primary slag formation kinetics (at a $T^{\mathrm{a}}$ of $1200^{\circ}$ to $1400^{\circ} \mathrm{C}$ ) if the magnesia silicate used is indeed a flux, as it is for DUNITE. In this case the desulfurization of pig iron is improved.

- Absorption of potassium vapours in the lower shaft and improvement of the kinetics of their fixation as $\mathrm{K}_{2} \mathrm{O}$ in the slag [3].

In recent years, Dunite has proven to be an excellent fluxing agent when used not only in the blast furnace but also in the sintering process, as it produces:

- Higher reducibility of the sinter that translates to a lower coke consumption in the BF.

- Better hot strength or lower coke consumption at the same hot strength in the sinter plant.

- Better homogeneity MgO distribution in the slag.

- Higher productivity of the sinter plant.

- Lower percentage of return sinter fines (return fines from the sintering process and screened off sinter before BF that are recycled to the sinter plant hoppers when Dunite mini-lumps are used (0/10, 1/10, 3/10 mm)).

- SOx off gas emissions reduction.

Figure 1. Effect addition Dunite as flux in Sinter

$$
\begin{aligned}
& \frac{\text { Plain Sinter }}{\checkmark \mathrm{BI}=1.5} \\
& \checkmark \text { Normal Operation }
\end{aligned}
$$

$$
\begin{aligned}
& \underline{\text { Sinter+Dunit@ Minilumps }} \\
& \checkmark \mathrm{BI}= \\
& \checkmark \text { Lower } \mathrm{SiO}_{2} \text { and } \mathrm{MgO} \text { in sinter }
\end{aligned}
$$

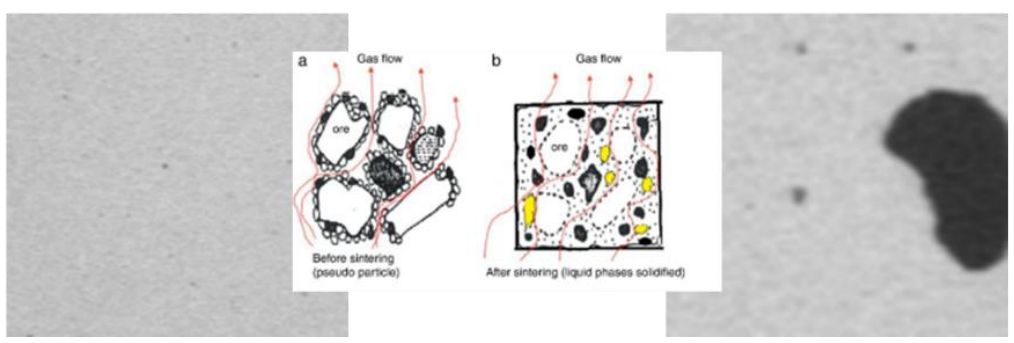




\subsection{Objective of Sinter Plant}

Sintering is one of the most commonly used agglomeration processes and the purpose of the sinter plant is to process fine grained raw materials into a coarse grained iron ore sinter, ready to be charged to the blast furnace. Sintering of fine particles into a porous clinker-sinter is necessary to improve the permeability of the burden, making reduction in the blast furnace easier and improving its operation.

It is necessary to product a high quality sinter that has high reducibility, this parameter is intimately related with the porosity and structure of the mineral phases, it reduces the intensity of blast furnace operations and reduces the coke consumption.

The sintering process is a combination of appropriate amounts of blended ore, fluxes and coke breeze, which after mixing and granulation are charged into a travelling grate. The coke at the top of the blend is ignited by gas burners and as the grate moves, air is sucked through the mixture, enabling combustion through the entire layer and completing sintering. At the end of the strand, the material is cooled by air and the finished sinter is size-screened. The obtained sinter need to have an adequate granulometry, with a size around $12-35 \mathrm{~mm}$, bigger particles are crushed to obtain smaller fractions, and those smaller than $5 \mathrm{~mm}$ are the return fines, which are recycled to the sinter hoppers. The final product of sinter with the appropriate size will be transported to BF as the main source of iron-contained material.

Figure 2. Schematic SINTER process

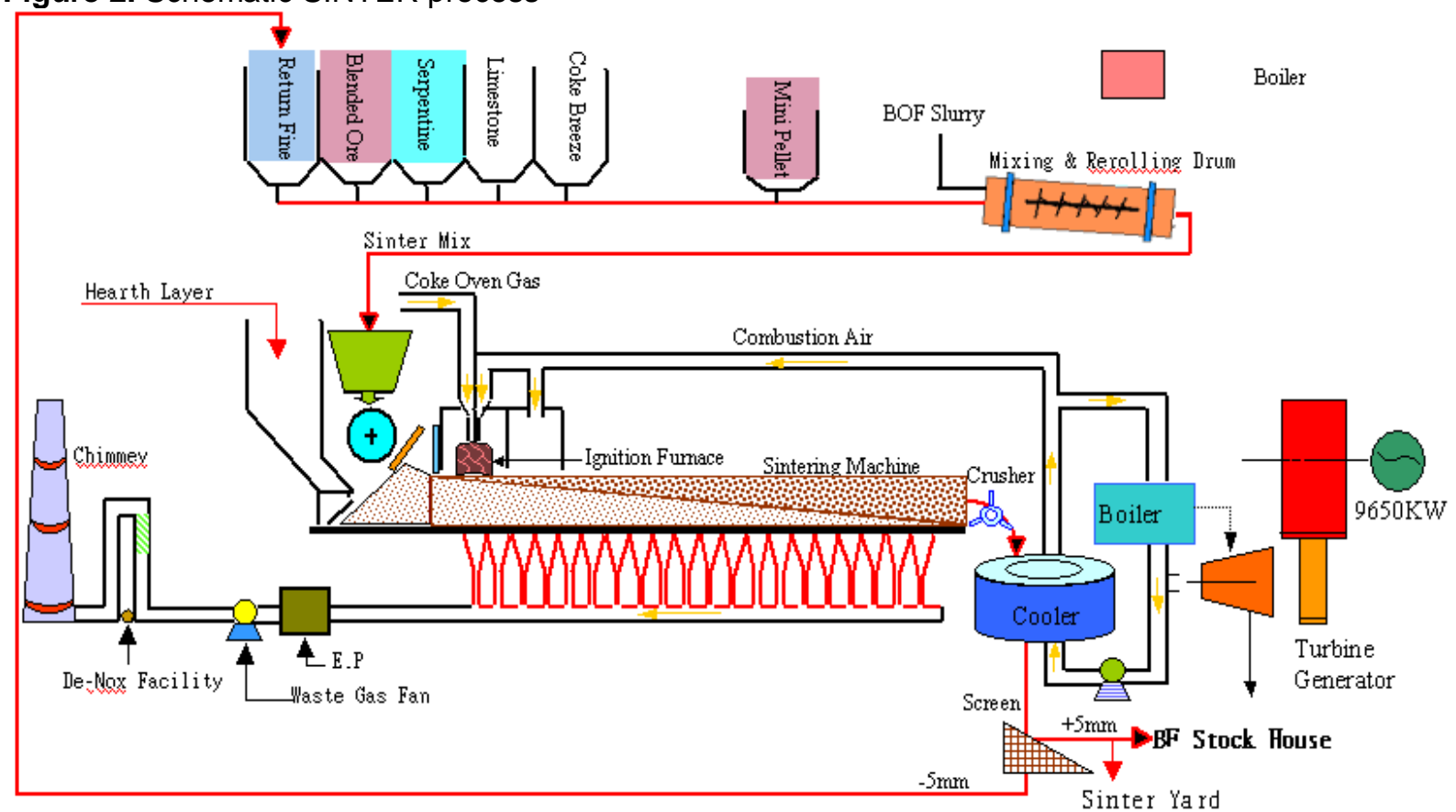

There are certain advantages of using sinters instead of using other materials which include recycling the fines and other waste products, to include flue dust, mill scale, lime dust and sludge. Sinter helps eliminating raw flux in the blast furnace, as it is introduced in the burden with the sinter. This reduces coke consumption in the furnace, as well as helps generating less slag, improving blast furnace productivity. 


\section{MATERIALS AND METHODS}

PASEK Dunite is an ultramaphic rock exploited in the north of Spain with a basic chemical classification, being olivine and serpentine its principal minerals. It is formed by orthopyroxene, clinopyroxene and olivine in variable proportions, with a previous amphibolitization of the rock and a paragenesis of hydrothermal alteration with serpentinization and talc conversion.

Exploited area corresponds with the less alteration zone (3). Rock has a medium to high grain size, equigranular, with frequent mesh textures in primary minerals developing secondary paragenesis. Through petrographic and geochemical study, following minerals and compositions are identified:

- Orthopyroxene: Classified by composition as enstatite, (Mg1.7Fe0.2)(Si1.96Al0.04O6) with traces of $\mathrm{Ca}, \mathrm{Cr}$ y $\mathrm{Mn}$ (<0.1 a.p.f.u).

- Clinopyroxene: Classified by composition as diopside (Ca0.95Mg0.9)(Si1.94Al0.06O6), with traces of Ti, Fe y $\mathrm{Na}(<0.2$ a.p.f.u).

- Olivine: Classified as olivine with s.s. Mg2+-Fe2+ (Mg1.5Fe0.5)(SiO4), with traces of $\mathrm{Al}$ (<0.01 a.p.f.u).

- Spinel: Classified as spinel showing solid solution between hercynite and magnesiochromite (Mg0.67Fe0.3)(Al1.55Cr0.32Fe0.1)O4.

- Opaque minerals: Generally magnetite and ilmenite with little size.

Figure 3. Micrograph with crossed nicols showing the texture of the rock.

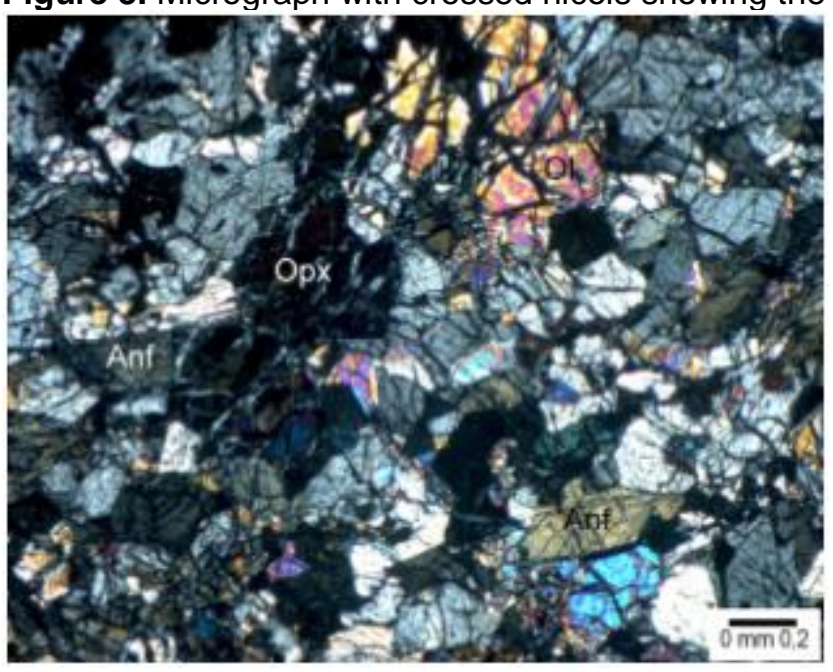

\subsection{Effect of fluxes in sinter properties.}

It is important for the BF operation to obtain a good quality sinter with the certain properties, being basicity and strength the major ones.

The blast furnace demands sinter with a chemical and a high cold compression strength (CCS), low reduction degradation index (RDI) and high reducibility index $(\mathrm{RI})$, in a very narrow band of chemistry variation, with the lowest fines content possible, and a good average size. Structural composition are very important, and it is good for the sinter to be stable so both primary and final slags possess adequate characteristics in terms of softening and melting temperatures, liquid temperature and viscosity for the stable operation of the blast furnace. 
For obtaining these effects, a good flux should:

- Be a homogeneous and hard stone.

- Have a high hot \& cold resistance to mechanical stresses (shatter / crushing / abrasion).

- Have the softening and melting points of a flux, not the ones of a refractory material.

- Have large porosity \& high absorption level.

- Have stable components with low melting points.

Appropriated fluxes for the Sinter plant could require low melting points to reduce energy consumption, increase the reactivity with the other raw materials in the Sinter mix, increase the sinter strength and reduce the return of fines to the sinter plant. In order to obtain the characteristics mentioned above, is necessary for the fluxes to have a good TI (Tumbler Index). The tumbler index determines the cold strength of the sinter, the size reduction due to impact and abrasion during the handling and transportation of the sinter, as well as in the blast furnace process. It is required the less possible generation of fines, as they could obstruct the blowing plugs, reduce the permeability of the burden in the blast furnace, lowering its reducibility which could end in a reduction of the productivity on both sinter and BF processes.

It is desired to have a homogeneous flux, with a homogeneous chemistry which allows the basicity control and with high absorption characteristics to combine with phosphorus, sulphur, silicon, etc,

A homogeneous chemistry that allows to control the basicity ( $\mathrm{Si}$ and $\mathrm{MgO}$ levels) and a high absorption characteristics to combine the flux with $\mathrm{P}, \mathrm{S}, \mathrm{Si}$, etc. are necessary.

\section{RESULTS AND DISCUSSION}

\subsection{Why PASEK Dunite is the best flux.}

Dunite is characterised by being a very homogeneous and hard stone. Its main characteristics are:

- Dunite has high hot and cold resistance to mechanical stresses, as shatter, crushing and abrasion.

- It has the softening and melting points of a flux, not of a refractory material. (Table 1).

- Dunite has a large porosity, which below $800^{\circ} \mathrm{C}$ reaches a $20 \%$. This insures a great reactivity and absorption level. (Figure 4).

- Stable components with low melting points (Table 2).

Table 1. Mechanical and thermal properties of Dunite

\begin{tabular}{|c|c|c|c|}
\hline \multicolumn{2}{|c|}{ Mechanical Properties } & \multicolumn{2}{|c|}{ Thermal Properties } \\
\hline Property & Typical & Property & Typical \\
\hline Tumble test & 95 & Softening point & $1200 \stackrel{\circ}{C}$ \\
\hline Hardness & $\begin{array}{ll}6.5 / 7 & \text { Mohs } \\
\text { scale } & \end{array}$ & Melting point & $1450 \stackrel{\circ}{C}$ \\
\hline
\end{tabular}


Figure 4. Aspect of a calcined Dunite.

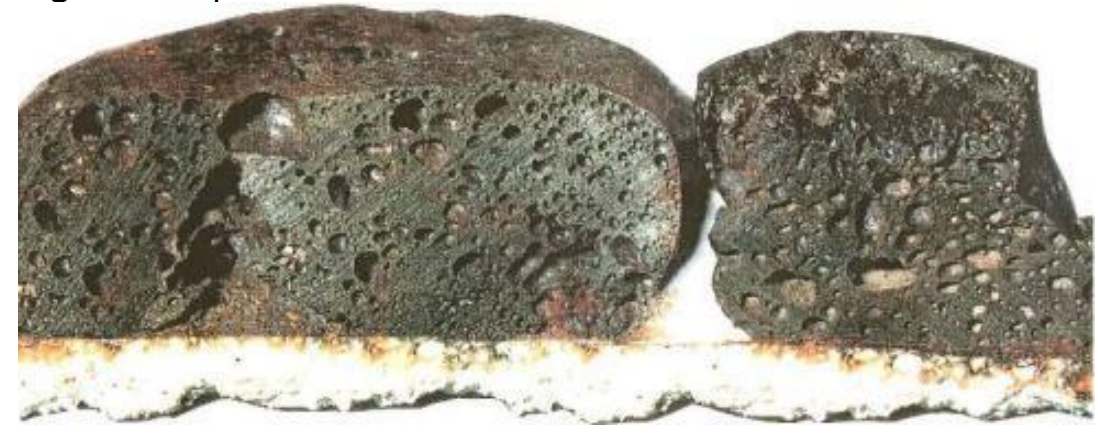

Table 2. Chemical analysis of PASEK Dunite

\section{Chemical analysis}

\begin{tabular}{|l|l|}
\hline Component & Typical \\
\hline $\mathrm{MgO}$ & $37 \%$ \\
\hline $\mathrm{SiO}_{2}$ & $40.5 \%$ \\
\hline $\mathrm{Fe}_{2} \mathrm{O}_{3}$ & $8.3 \%$ \\
\hline $\mathrm{CaO}$ & $1.9 \%$ \\
\hline $\mathrm{Na}_{2} \mathrm{O}+\mathrm{K}_{2} \mathrm{O}$ & $<0.20 \%$ \\
\hline L.O.I & $8.5 \%$ \\
\hline
\end{tabular}

\subsection{Highest value in use of fines in sinter.}

The Dunite used as a flux in the Sinter has no fines regarding it is very lumpy material. Less than $5 \%$ of the total material is under $1 \mathrm{~mm}$. Dunite is strong and lumpy so no powder is generated. (Figure 5).

Figure 5. Sieve analysis of a typical PASEK Dunite used in SINTER process. 


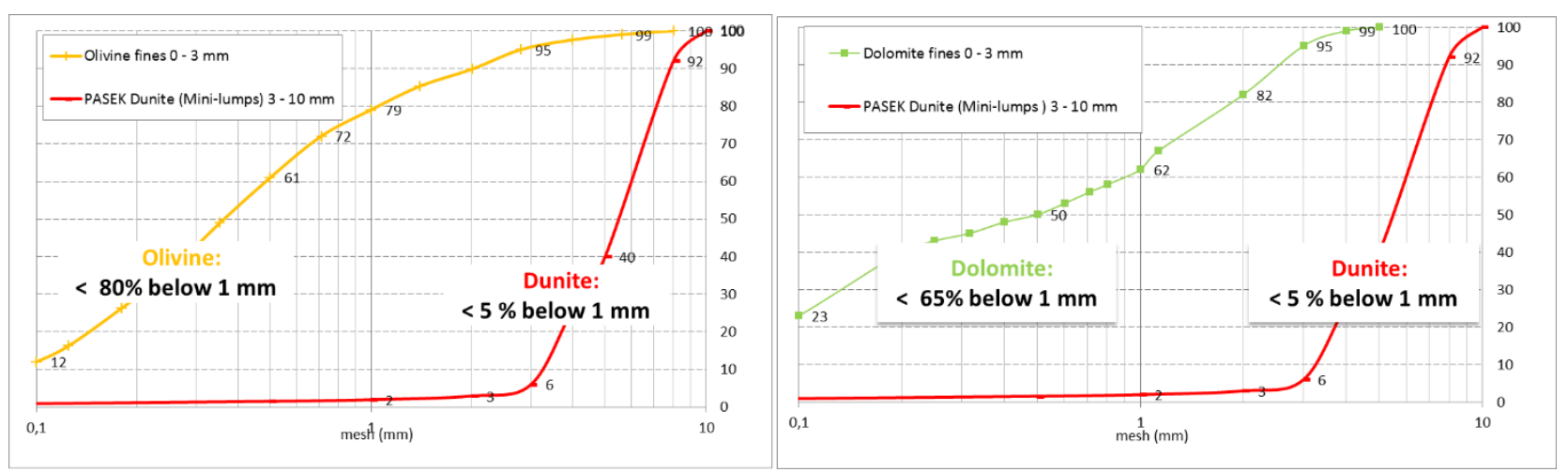

In addition, the use of Dunite implies less energy consumption in comparison with other fluxes which need more energy to react, this can lead to economical savings. The consumed energy needed by different fluxes to be heated from 22 to $1400^{\circ} \mathrm{C}$ is shown in the following figure. Dolomite energy consumption is around $45 \%$ higher than the one for Dunite, therefore is possible to achieve economical savings substituting Dolomite for Dunite as a flux. (Figure 6).

Figure 6. Results of the thermogravimetric analysis for different fluxes used in the BF.

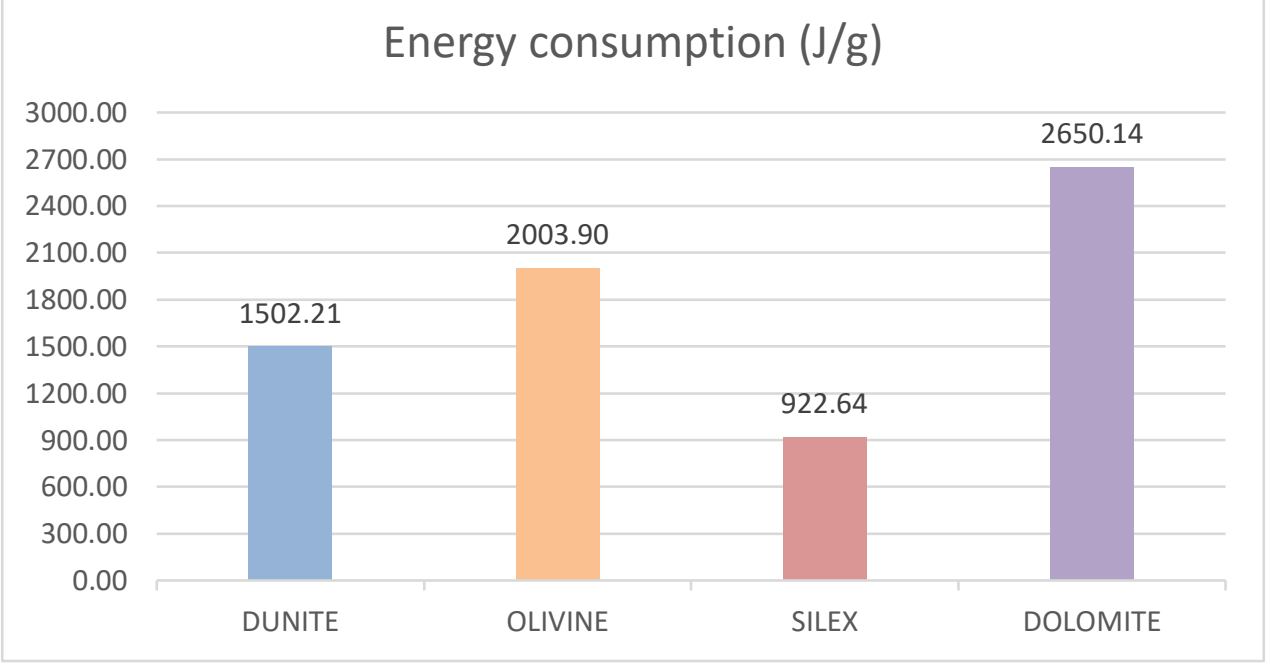

\subsection{Magnesium silicate behaviour in the Sinter process}

Taking into account the working conditions in the Sinter Plant, magnesium silicate used as a flux will be subjected to blast furnace similar conditions. Studies with experimental blast furnaces have shown that the magnesium silicates undergoes a series of reactions with the molten metal and its impurities to form a siliceous melt to trap undesired elements. In the early stages, magnesium silicate develops a border with magnetite and liquid phase that gradually develops phases as wustite, magnesiumferrite and sodium and potassium silicates passing to the slag (Figure 7). The cast with free silica also helps trapping impurities. In the final stages, the magnesium silicate is completely dissolved and its components become part of the slag

\section{Figure 7.}

Forsterite core - inclusions of

$$
\text { * }
$$

iron rich olivine:

- $\mathrm{Fe}_{2} \mathrm{SiO}_{4}$

$\mathrm{e}_{2} \mathrm{SiO}_{4}$ 
Figure 8. In the left picture, the silicate has not reacted completely and is surrounded by a rim of glass (melt) of siliceous composition, with some magnesium and iron oxides. In the right picture, magnesium silicate has almost completely consumed, giving place to a melt surrounded by droplets of metallic iron which can be in turn surrounded by a siliceous melt.

Several studies performed using Dunite as a flux in the sinter mix, have demonstrated that part of this added Dunite reacts during the sintering process, leaving some inert Dunite after the process that would reach the BF as a lump.

- Dunite $<5 \mathrm{~mm}$ reacts in the Sinter

- Dunite $>5 \mathrm{~mm}$ reaches the blast furnace as a lump.

Figure 9. SEM image of Sinter mix with Dunite

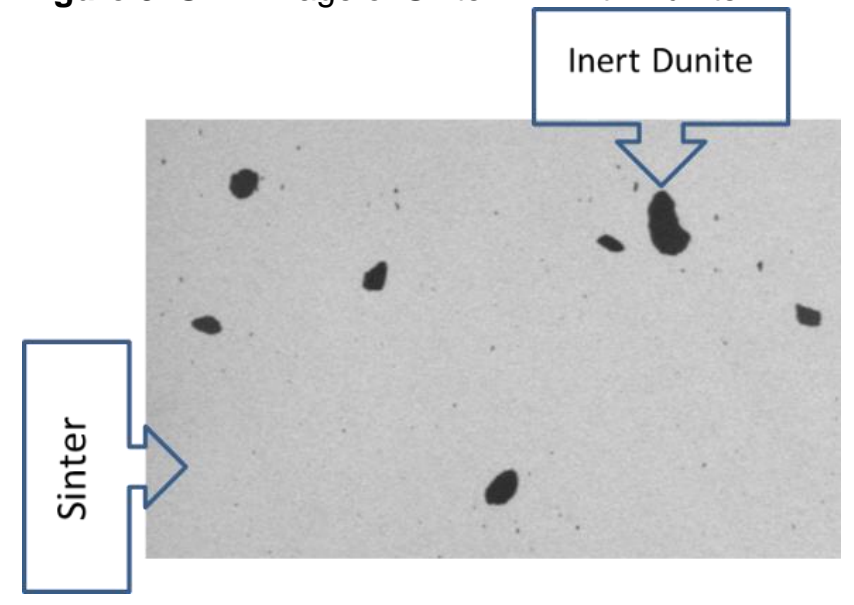

\subsection{Dunite Industrial Test}

An industrial test using Dunite mini-lumps instead of Olivine as $\mathrm{MgO}$ bearing flux in the sinter plant were performed, and the results shown that:

- The value of ISO $(+6.3 \mathrm{~mm})$ remains constant and between $80-85 \%$.

- The NTZ $(-3.15 \mathrm{~mm})$ value improves about $6 \%$ in comparison with the sinter with Olivine.

- The screening sinter fines decreases about 3\%

- Sintering performance remains constant during the trials

Figure 10. Result industrial trials with Dunite 


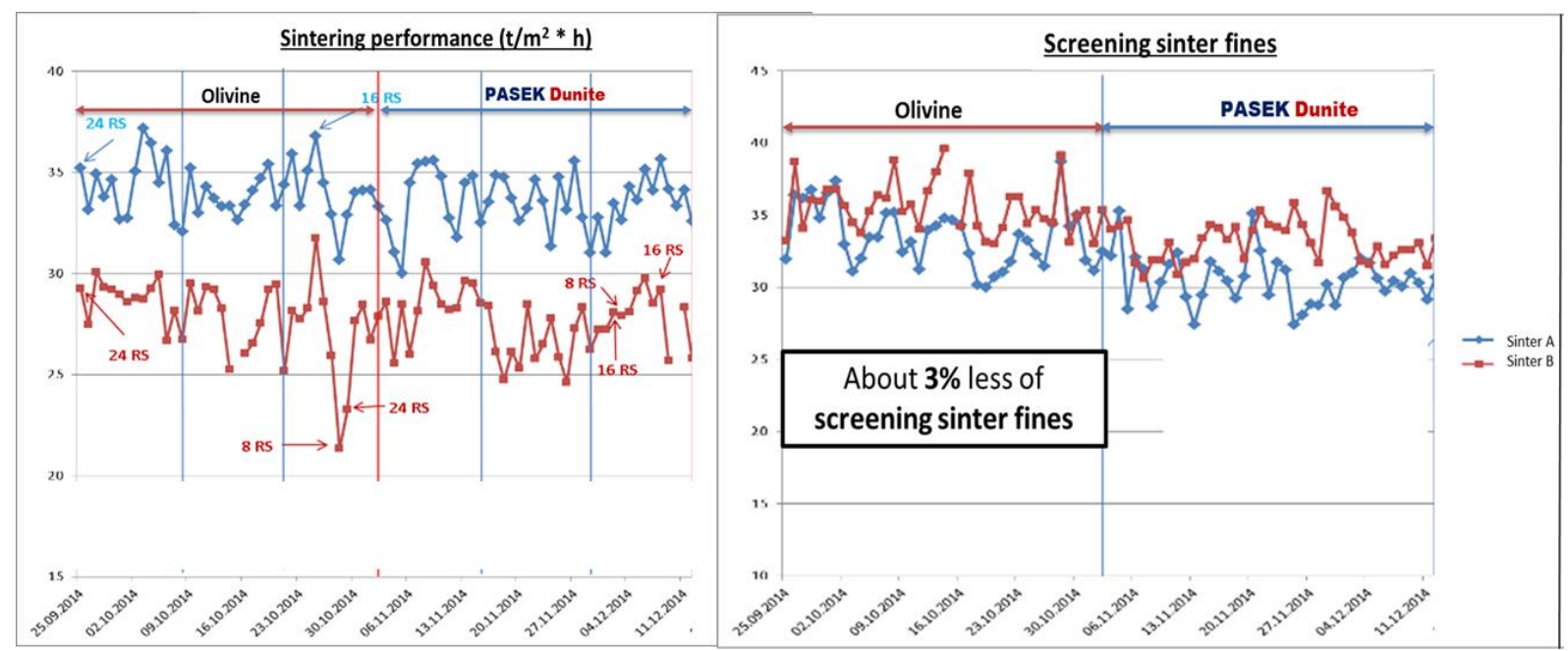

Describe succinctly the equipment and procedures used, as the literature and the statistical methods and the corresponding literature, as the case demands.

\section{CONCLUSION}

PASEK Dunite is a good flux in Sinter and Blast Furnace processes. The use of Dunite in Sinter mix allows:

1. Less generation of powder in comparison with other fluxes due to the lumpy characteristics of Dunite.

2. Dunite improves sinter quality making sinter stronger. This leads to a reduction of the return sinter fines, which implies an increase in the productivity of the sinter plant.

3. Sinter disintegration is reduced on the upper part of Blast Furnace, improving the permeability and consequently the fuel rate is reduced.

4. Less standard deviation of $\mathrm{MgO}$ content in sinter from Dunite than from Olivine.

\section{Acknowledgments}

Geology Department. University of Oviedo.

\section{REFERENCES}

1 Industrial Efficiency Technology Database [website]. JFE $21^{\text {st }}$ Century Foundation, 2003 [access: March,1 st]. Available at http://ietd.iipnetwork.org/content/bof-bottom-stirring

2 Corretgé Castañon, L.G., Rubio Ordóñez, A. Transformación mineral en procesos de calentamiento. Estudio térmico difractográfico de una muestra de dunite. Oviedo: University of Oviedo; 2011.

3 Caballero, R., Rubio, A., García-Arias, M., Corretgé, L.G. Utilización de la dunita a temperaturas elevadas. Comportamiento térmico de las fases hidratadas. University of Oviedo and Pasek Minerales; 2010.

4 Ryösä, E. Mineral reactions and slag formation during reduction of olivine Blast Furnace pellets. Dissertations from the Faculty of Science and Technology, 2008. Uppsala Universitet, 575. 